\title{
Francesco Spandri, Du malaise existentiel à la panacée économique: Stendhal, Balzac, l'improper, l'argent
}

\section{Marco Stupazzoni}

\section{Q OpenEdition}

1 Journals

\section{Edizione digitale}

URL: http://journals.openedition.org/studifrancesi/1559

DOI: 10.4000/studifrancesi. 1559

ISSN: 2421-5856

Editore

Rosenberg \& Sellier

\section{Edizione cartacea}

Data di pubblicazione: 1 novembre 2014

Paginazione: 619

ISSN: 0039-2944

\section{Notizia bibliografica digitale}

Marco Stupazzoni, « Francesco Spandri, Du malaise existentiel à la panacée économique: Stendhal, Balzac, l'improper, l'argent », Studi Francesi [Online], 174 (LVIII | III) | 2014, online dal 01 novembre 2014, consultato il 18 septembre 2020. URL : http://journals.openedition.org/studifrancesi/1559; DOI : https://doi.org/10.4000/studifrancesi.1559

Questo documento è stato generato automaticamente il 18 settembre 2020.

\section{(c)}

Studi Francesi è distribuita con Licenza Creative Commons Attribuzione - Non commerciale - Non opere derivate 4.0 Internazionale. 


\title{
Francesco Spandri, Du malaise existentiel à la panacée économique: Stendhal, Balzac, l'improper, l'argent
}

\author{
Marco Stupazzoni
}

\section{NOTIZIA}

FRANCESCO SPANDRI, Du malaise existentiel à la panacée économique: Stendhal, Balzac, l'improper, l'argent, «Romantisme», n. 160, $2^{\mathrm{e}}$ trimestre 2013, pp. 99-112.

1 Gli elementi che sono alla base del rapporto dialogico tra Rome, Naples et Florence di Stendhal e La Maison Nucingen di Balzac, un rapporto fondato, pur nella particolarità dei loro significati, sulla «rencontre de l'improper et de l'argent» (p. 99), forniscono all'autore i presupposti tematici per un interessante studio sulle articolazioni semantiche e ideologiche presenti tra i due testi sulla base delle prospettive e delle implicazioni esistenziali ed economiche che esse incarnano nelle loro rispettive espressioni letterarie.

2 L'anglofobia stendhaliana, osserva F. Spandri, «met cet improper de filiation britannique au service d'une critique de la civilisation individuelle contre le poids suffocant des règles sociales» (p. 105). Ne La Maison Nucingen, Balzac investe questa espressione aggettivale inglese di nuovi e differenti significati collocandola all'interno di un discorso bilaterale sul denaro nell'ambito di una concezione economica «"omniconvenante" qui embrasse tous les styles, toutes les existences en son sein» (p. 106). In questo dibattito a distanza tra Balzac e Stendhal, la scissione tra individuo e società sembra potersi risolvere soltanto in termini economici. Ne La Maison Nucingen, infatti, osserva l'autore in conclusione, l'«argent balzacien répond une fois pour toutes aux objections élevées par le voyageur italophile contre la civilisation, dans la mesure où il la résout en faveur d'un capitalisme bien hospitalier [...], d'un capitalisme 
élastique, qui excelle à s'adapter aux circonstances, d'un capitalisme raisonnable, qui parvient malgré tout à se faire accepter, ou mieux encore vénérer» (pp. 111-112). 